\title{
The Education and Tourism Value of the Ethnic Minorities Living in Heilongjiang for Generations Based on Cultural Protection
}

\author{
$\mathrm{Hao} \mathrm{Wu}$ \\ Heihe University \\ Heihe, China
}

\begin{abstract}
Heilongjiang is a province with relatively concentrated ethnic minorities in China. There are ten ethnic minorities living here for generations. In this context, fully exploiting the cultural heritage of Heilongjiang's ethnic minorities to promote the development of cultural and educational undertakings of it and opening up the cultural resources of ethnic tourism resources is a very important issue in the protection and inheritance of ethnic minorities in Heilongjiang. However, Heilongjiang Province is still lagging behind in the education advancement of ethnic minority cultures and the development of tourism resources for ethnic minorities. Ethnic education has become a relatively weak link in cultural protection, and many excellent national tourism resources cannot be fully obtained development and utilization. In view of this, it is of great practical significance to carry out in-depth study on the national cultural education of ethnic minorities living in Heilongjiang Province and the excavation of ethnic tourism resources.
\end{abstract}

Keywords-cultural protection; ethnic minorities living in Heilongjiang for generations; education; tourism

\section{INTRODUCTION}

Heilongjiang Province is located in the northeast of China. It is a province with rich national culture and distinct folk customs. According to relevant data, there are 53 minority nationalities in Heilongjiang Province. Among them, there are 10 inhabitant minorities have lived in this fertile land for generations, such as Manchu, Hui, Mongolian, Korean, Xibe, Daur, Ewenki, Oroqen and Kirgiz nationalities. [1] Although the number of ethnic minorities in Heilongjiang Province is relatively large, the overall population is relatively small, and the number of ethnic minorities accounts for only about $5 \%$ of the population in Heilongjiang Province. In the fifth census of our country, the population of Kirgiz ethnic group in Heilongjiang province is only 1473, and it is also the minority nationality with the lowest population in all the inhabitants of Heilongjiang province. Because the population of the inhabitant ethnic group is very small, they often live together with Han or other ethnic minorities. In the long-term contact with the Han culture, many traditional cultures of the inhabitant minorities have been diluted, and some of the traditional cultures of them have been gradually integrated into the Han culture, gradually making some distinctive national cultures lose their original characteristics. In view of this, promoting the diversification of the cultures of the inhabitant minorities in Heilongjiang has become a very important issue for the current national culture education and the development of ethnic cultural tourism.

\section{TRAditional CUlture EdUCATION AND FolKLORE TOURISM RESOURCES OF MINORITIES LIVING IN HEILONGJIANG PROVINCE FOR GENERATIONS}

\section{A. Investigation on the Traditional Culture Education of the Inhabitant Minorities in Heilongjiang Province}

One of the most important ways of cultural inheritance is school education, and the scale of ethnic minority schools and the proportion of ethnic minority students can largely reflect the strength of schools in the implementation of ethnic culture.

Firstly, in terms of the number of ethnic schools, there are 158 schools in Heilongjiang Province, and 95 schools with students under 200, accounting for about $59 \%$ of all ethnic schools. Due to the large number of ethnic minorities living in Heilongjiang and the great differences among ethnic groups, the overall number distribution of ethnic schools also shows an unbalanced phenomenon. For example, the population base of the Korean nationality in Northeast China is relatively large, so there are more Korean schools and its traditional culture of ethnic minorities has unique inheritance advantages, while the Ewenki and Oroqen ethnic minorities with relatively small population base do not have such inheritance advantages. In some areas of Heilongjiang Province, ethnic minority schools even have only one ethnic school in villages and towns. Therefore, many ethnic minorities with a small population base set up ethnic primary schools with ethnic residences and villages as basic units.

Secondly, as far as the composition of ethnic schools is concerned, many of them are no longer pure ethnic schools, because the composition of students in ethnic schools is very complicated. The Han students in most ethnic schools are often inversely related to the population base of ethnic minorities, which leads to the fact that some ethnic minority schools with a small population base have more Han students, but in some ethnic minority schools with a large population 
such as Koreans or Mongolians, the number of Han students is very small or there are no Han students.

Thirdly, ethnic culture education has a great relationship with its curriculum development. The development of modern ethnic school education can be divided into two parts. First, the basic curriculum teaching prescribed by the Ministry of Education. In this curriculum teaching, the syllabus tends to be taught in accordance with the national teaching standards as the focus of teaching. The other part is based on the school-based curriculum, mainly based on the local ethnic culture as the main teaching content, which plays a role in teaching supplement. The teaching setting is mainly viewed of national traditional culture education. Due to the large differences in the size of the national population and the tradition of national education, there are certain differences in the cognition of national culture in different regions, which also leads to disparities in the content of ethnic teaching in diverse regions. This will lead to greater divergences in the functions played by national education in the process of protecting national culture. Generally speaking, ethnic groups with a large population base can better integrate their own culture into the teaching process in national education. This is mainly because the people with large population bases tend to have a better national cultural atmosphere, which is a favorable condition. The national atmosphere is a very important prerequisite in the process of national cultural heritage. The Manchu and Korean ethnic groups in Heilongjiang have a relatively large population base and a high degree of national culture, which provides a powerful platform for the protection and inheritance of national culture. Although some ethnic minorities with a small population base have made great efforts to protect their culture in their teaching practice, in the development of the teaching content of their ethnic schools, the national culture still has a relatively small proportion, which makes the actual effect not obvious.

Finally, subject to the carrier of the language, the inheritance of ethnic minorities' education achieves different effects. Among the ethnic minorities in Heilongjiang, only Mongolian, Korean and other several ethnic groups have their own spoken and written languages. So, the school education of these ethnic groups can carry out bilingual education very well, which has played a very good role in promoting the inheritance of national languages and the understanding and learning of the national language of the students; for example, some of the inhabitants living Heilongjiang for generations, such as the Daur, Oroqen, Kirgiz, Ewenki, and Hezhe, do not have their own language. Although these ethnic schools also carry out bilingual teaching, the inheritance effect of national education is not ideal due to the restriction of words.

\section{B. Characteristics of Tourism Resources of Ethnic Minorities Living in Heilongjiang for Generations}

The minority folk custom tourism resources in Heilongjiang Province are a kind of folk cultural matters formed by the ethnic minorities in the process of production and life. They can be roughly divided into material folk tourism resources, spiritual national tourism resources and social ethnic tourism resources. Clothing, diet, residence, handicraft and so on belong to tourism resources of material folklore, while spiritual folklore tourism resources mainly refer to religious beliefs, national totems, national ancestor worship culture with folklore characteristics. Some national myths, legends and folk literature are also included. In addition, some traditional festivals of ethnic minorities belong to social folk tourism resources. These folklore cultures and phenomena not only have distinct national characteristics, but also are excellent symbols of historical inheritance. With the development and progress of Heilongjiang modern tourism industry, many tourism products with folk characteristics have been constantly excavated and developed, which makes the folk culture of many ethnic minorities gradually become the characteristic tourism resources of Heilongjiang.

1) Various types of folklore resources of ethnic minorities living in Heilongjiang for generations: There are many ethnic minorities in Heilongjiang Province, among which there are ten inhabitant ones having lived here for generations. The cultural resources of the whole inhabitant ethnic groups show the characteristics of rich and diverse types and distinctive folklore features. Among them, farming, nomadism, diet, residence and other aspects of national culture are the essence of cultural heritage. For example, Korean farming and Mongolian animal husbandry and other folk customs everywhere reflect the diversity of the inhabitant culture, and many of the inhabitant ethnic minorities' clothing and diet culture is colorful and unique, such as Manchu cheongsam, Korean white clothes, Oroqen's animal clothing, Hezhe's fishing and hunting customs have rich national cultural connotations.

In Heilongjiang, many ethnic minorities living here have the customs of natural worship, totem worship and ancestor worship. The traditional taboo customs gradually formed in the production and life of some ethnic groups are also the common traditional cultural phenomena of ethnic minorities. These primitive ethnic cultures undoubtedly have mystery and great attraction to the outside world, and the myths and legends inherited by some ethnic minorities also embrace the characteristics of northern folklore.

2) Concentrated distribution of folklore resources of ethnic minorities living in Heilongjiang for generations: In Heilongjiang Province, ethnic minorities are distributed all over the province, but the distribution of some inhabitant ethnic minorities is relatively concentrated. For example, Dulbert Mongolian Autonomous County in Heilongjiang Province is the only county with Mongolian as the main animal husbandry base in the country; Meilis in Qiqihar is the only Daur ethnic area in the city of the country, while the Oroqen ethnic minorities are mainly concentrated in several counties, such as Huma Aihui, Sunk and Jiayin. Moreover, Heilongjiang has also established several townships inhabited by ethnic minorities in the province. Although Heilongjiang Province has a relatively small area where the local minorities are concentrated, and the 
distribution of folk culture is islet-like, the atmosphere of folk culture in the area where the local minorities are concentrated is very strong and enjoys a very rich folk cultural heritage. These cultures are excellent folk tourism resources in Heilongjiang Province.

\section{EXPLORATION ON EDUCATION AND TOURISM VALUE DEVELOPMENT MODEL OF MINORITIES LIVING FOR GENERATIONS BASED ON THE PROTECTION OF ETHNIC CULTURE}

\section{A. Construction of the Education System of Folklore Culture}

Firstly, it's necessary to gradually strengthen the construction of school-based curriculum of ethnic culture in ethnic schools. When choosing the content of folk culture, some content which is compatible with the characteristics of the times and easy to be accepted by students shall be used as school-based curriculum in ethnic schools, so as to avoid imposing some outdated traditional culture on the new generation of ethnic students. This requires the combination of traditional cultural content and modern social and economic development situation to be found out. Cultural heritage is an evolutionary process. Therefore, only by putting traditional culture in the dynamic changes of the times can cultural heritage and traditional culture development be truly realized.

Secondly, it is suggested that the relevant government departments take the opportunity of the festival celebrations of ethnic minorities to fully explore their social value in education and use them rationally to create a strong national atmosphere for the national schools through ethnic festivals. On campus, all the students of the school will appreciate the charm of national culture. In addition, it is advisable to deepen the education of national culture and strengthen the cohesion among different minorities by organizing mass ethnic activities. At the same time, it's wise to add another educational mode as a supplementary form of education and teaching in ethnic schools.

Thirdly, the education of ethnic schools has been placed great expectations by the society for the inheritance of ethnic cultures, but in the actual inheritance of ethnic cultures, there are still many difficulties. How to strengthen the propaganda and protection of ethnic cultures is a problem all related people need to think about urgently. Ethnic culture education cannot be confined to the campus only. Ethnic education in families should also be highly valued, so that family members can actively participate in the inheritance of national culture. Nowadays, with the accelerated development of modern urbanization, the impact of mainstream culture on traditional culture makes parents of many families know little about traditional culture. Yet, there is a fact that the national cultural fortress shall be stuck to with family as the basic unit, so that the elder parents of all students can play an important role in propaganda and inheritance, and let each family member become the bridge of national cultural inheritance, holding fast to the fortress of inheritance of national culture.
The awareness of the national culture is constantly improving, which is also the basis for the realization of the national cultural heritage. The main purpose of national education is to let students realize the connotation of national culture in education, to let them remember these excellent traditional cultures and feel the hardship and greatness of their ancestors' entrepreneurship through education. By the inheritance of national culture, the students' sense of national identity and patriotic enthusiasm can be enhanced. In the meantime, the cohesion of the new generation of nations will be strengthened. It can be seen that the education of national culture, the strengthening of national consciousness and the promotion of the identity of the motherland culture are all important contents of national education, and also the main purpose of our inheritance and protection of national culture [2].

\section{B. Development Model of Tourism Value of Ethnic Minorities Living in Heilongjiang for Generations}

1) On-the-spot folk village model: These modes not only help to protect and develop ethnic tourism resources on the spot, but also boost original ecological tourism resources development. In Heilongjiang Province, some typical folk villages of ethnic minorities living here for generations are selected as field folk villages, and their tourism value is developed on the basis of fully protecting these folk villages. In this way, the original ecological life style of the ethnic group can be displayed to the outside world, the authenticity of the ethnic culture can be showed, and the original form of the national culture can be well protected. As we all know, folklore is a relatively stable cultural matter with national characteristics produced in the process of national or social groups' life and production. Therefore, if tourists want to truly experience the connotation of national culture and its unique national charm, they must experience it personally. This mode of development of tourism value does not need to undergo large-scale civil engineering transformation, and will not destroy the original ecology. Beyond protecting the original national culture, it plays a leading role in the economy of backward ethnic villages.

2) Simulated folk village model: The main mode is to make the resources of ethnic villages into a theme park for display and make construction in a suitable area, showing the national culture regionally according to different styles. The main manifestation of this mode is artificial landscape. In this mode, the national culture is concentrated and copied to help visitors to watch the characteristics and essence of national culture in the shortest time [3]

3) Folk museum model: This mode mainly shows the value of national tourism through the agglomeration of national culture, and displays and propagandizes the national culture such as production, life, transportation, clothing and belief of the inhabitants and their material objects to the outside world under the solid mode. 


\section{CONCLUSION}

The national culture of the ethnic minorities living in Heilongjiang Province is a very important part of the folk culture of our country and even the world. Education is the carrier of cultural inheritance and the way of cultural development. Therefore, firstly, it's essential to do a good job in the education of national culture so that the excellent culture can be inherited and protected. In view of the imperfections in the construction scale and educational system of the existing ethnic minority schools in Heilongjiang Province, the author believes that the development can be promoted by establishing a national rural education system dominated by cultural protection, strengthening the school-based curriculum of ethnic schools, and creating a good atmosphere for the protection of ethnic cultures in schools and society; the tourism value of national culture can be advanced through reasonable development methods to promote the growth of the regional economy of the inhabitants. It is also necessary to build national tourism ecology with the living minorities as the core, adhere to the principles of traditional cultural education and cultural tourism of the living minorities, finally forming a cultural protection and inheritance undertaking with the education and tourism of the living minorities in Heilongjiang as the core.

\section{REFERENCES}

[1] Cheng Shuhua, Li Xin. A Journey to Find the Root of Ethnic Minority Culture: A Review of Field Investigation and Research on Ethnic Minority Culture of Less Population in Heilongjiang Province from the Perspective of Urbanization [J]. The Border Economy and Culture, 2018(01):8-9. (in Chinese)

[2] Fan Xiaofeng. On the Protection and Development of Minority Cultural Tourism Resources in Western Heilongjiang Province Taking Qiqihar Area of Heilongjiang Province as an Example [J]. Heilongjiang National Series, 2015(04):130-134. (in Chinese)

[3] Zhou Jiayu, Li Qiong. Folk Beliefs and Rural Social Life in Underdeveloped Areas - Taking the Folk Beliefs of Minorities Living in Lincang for Generations as an Example [J]. Heilongjiang Chronicles, 2015(01):227-228+230. (in Chinese). 